Int. J. Electrochem. Sci., 14 (2019) $8419-8428$

International Journal of

ELECTROCHEMICAL

SCIENCE

WwW.electrochemsci.org

\title{
Electrochemical Biosensor Based on Myoglobin for Trichloroacetic Acid and Nitrite Determination
}

\author{
Guiling Luo ${ }^{1}$, Hui Xie ${ }^{1}$, Hamza Abdalla Yones ${ }^{1}$, Si Mi ${ }^{1}$, Binghang Li $^{1}$, Yubao Wang ${ }^{1}$, \\ Pengying Chen ${ }^{1}$, Guangjiu Li ${ }^{2}$, Wei Sun ${ }^{1 *}$ \\ ${ }^{1}$ Key Laboratory of Water Pollution Treatment \& Resource Reuse of Hainan Province, Key \\ Laboratory of Functional Materials and Photoelectrochemistry of Haikou, College of Chemistry and \\ Chemical Engineering, Hainan Normal University, Haikou 571158, P R China \\ ${ }^{2}$ Key Laboratory of Optic-electric Sensing and Analytical Chemistry for Life Science of Ministry of \\ Education, College of Chemistry and Molecular Engineering, Qingdao University of Science and \\ Technology, Qingdao 266042, China \\ *E-mail: sunwei@hainnu.edu.cn
}

doi: $10.20964 / 2019.09 .37$

Received: 6 April 2019 / Accepted: 27 June 2019 / Published: 31 July 2019

In this paper the effect of gold nanochains (AuNCs) on direct electron transfer of Myoglobin (Myb) was studied in detail. A Nafion polymer dispersions, Myb solution and AuNCs solution were dropped on carbon ionic liquid electrode (CILE) in sequence to develop a new working electrode. AuNCs have high electrochemical activity with excellent biocompatibility, which serve as electron transfer path for intensifying electrochemical response of Myb. In electrolyte a pair of symmetrical redox peaks of Myb was displayed on cyclic voltammogram and electrochemical performance of this modified electrode was investigated. Myb on electrode surface exhibited good electrocatalytic reduction activity to trichloroacetic acid (TCA) and sodium nitrite $\left(\mathrm{NaNO}_{2}\right)$. The electrocatalytic current displayed a linearity regression behavior to TCA concentrations from 2.0 to $400.0 \mathrm{mmol} / \mathrm{L}$ with the detection limit of $0.26 \mathrm{mmol} / \mathrm{L}$, to $\mathrm{NaNO}_{2}$ concentrations from 0.04 to $1.8 \mathrm{mmol} / \mathrm{L}$ with the detection limit of 0.013 $\mathrm{mmol} / \mathrm{L}$. Consequently, this paper extended the utilization of AuNCs in construction of an excellent platform based on electrocatalysis of redox enzymes.

Keywords: Gold nanochains; Direct electrochemistry; Myohemoglobin; Electrocatalysis

\section{$\underline{\text { FULL TEXT }}$}

(C) 2019 The Authors. Published by ESG (www.electrochemsci.org). This article is an open access article distributed under the terms and conditions of the Creative Commons Attribution license (http://creativecommons.org/licenses/by/4.0/). 